\title{
Percepções sobre a linguagem museológica do Museu Histórico de Londrina: a exposição "Cuidar, Curar, Lembrar - memória da saúde em Londrina" e as representações de mulheres.
}

\author{
Perceptions about the museological language of the Historical \\ Museum of Londrina: the exhibition "Caring, Healing, Remembering - \\ memory of health in Londrina" and representations of women.
}

\section{Bruno Sanches Mariante da Silva*}

\section{RESUMO}

Os museus históricos, como os monumentos, já foram entendidos como imagens que as sociedades produzem para o futuro. No entanto, esta concepção dos museus enquanto espaços mantenedores e guardiães da memória de uma comunidade ou localidade começa a ser revista. A cidade de Londrina, mesmo que bastante nova, conserva através de diferentes meios o elogio à memória de determinados grupos chamados de 'pioneiros'. A contestação de tais práticas memorialísticas e a inclusão de novos atores é bastante polêmica e custosa. Desse modo, o presente artigo traz em seu escopo refletir acerca das representações de mulheres na linguagem do Museu Histórico de Londrina. Para tal propõe-se a analisar a mais recente exposição temporária que este espaço abrigou: "Cuidar, Curar, Lembrar memória da saúde em Londrina". Assim, quer-se investigar com qual(ais) linguagem (s) museológica o MHL alinha-se e como apresenta-se ao público.

Palavras-chave: Museus. Londrina. Representações de Mulheres. Memória. Saúde Pública.

* Doutorando junto ao programa em História e Sociedade da Universidade Estadual Paulista - Campus de Assis. Bolsista CAPES. 


\section{ABSTRACT}

The historical museums, such as the monuments, have been understood as images the societies produce for the future. However, this concept of museums as maintainers and guardians of the memory of a community or a locality is been revised. The city of Londrina, even though fairly new, preserves by various means a praise of the memory of certain groups, called 'pioneers'. The challenging of such memorial practices and inclusion of new actors is quite controversial and costly. Thus, this paper aims to reflect on the representations of women in the language of the Historical Museum of Londrina. To this end, it is proposed to analyze a temporary exhibition placed in that Museum: "Caring, Healing, Remember memory of the health in Londrina." Therefore, we will investigate what (s) language (s) the MHL aligns to and presents itself for the public.

Keyword: Museums. Londrina. Women representations. Memory. Public health

"Eu vejo um museu de grandes novidades" era a previsão do jovem poeta do rock brasileiro Cazuza na década de 1980 em uma de suas canções. Advertência similar é a do historiador francês François Hartog, para quem estamos a um passo de preparar o museu do amanhã (HARTOG, 2006). Esse passo, contudo, já foi dado. O Museu do Amanhã surge como grande obra arquitetônica na região portuária da cidade do Rio de Janeiro. A proposição e construção deste museu vêm corroborar a emersão de novas concepções e linguagens museológicas, fenômeno que há tempos é discutido por museólogos em conjunto com antropólogos, historiadores e sociólogos e outros profissionais. Essas transformações são sentidas em museus de ciências e tecnologia, assim como em museus de arte e históricos.

O "Museu do Amanhã", cuja construção está para ser concluída, integra um esforço públicoprivado para revitalização da região portuária da capital fluminense. Trará em si um novo conceito de museu, uma vez que será caracterizado como um museu do impacto da ação humana no universo, isto é, pensar como o ser humano interfere no ambiente e vislumbrar experiências futuras. Tal proposta proporcionará grande interatividade com o visitante.

Pensando a contemporaneidade de proposituras de novas linguagens nos museus, no presente artigo procuraremos empreender breve análise da exposição intitulada "Cuidar, Curar, Lembrar - memória da saúde em Londrina" realizada pelo Museu Histórico de Londrina Padre Carlos Weiss em sua galeria de Exposições Temporárias no período de 29 de março a 31 de julho de 2012. A ideia central do artigo é refletir sobre a concepção museológico do MHL, enfocando, especialmente, a compreensão acerca das representações de mulheres na referida exposição e, para tal, desenvolveremos, primeiramente, uma descrição e análise do conjunto da exposição. 


\section{1 - Museu(s)}

As transformações no conceito de museu não são recentes. Etimologicamente museu deriva da palavra grega mouseion, que na Grécia Antiga designava o templo das nove musas, todas filhas de Zeus com Mnemosine (deusa da memória). Essas musas representavam os diferentes campos do saber ligados às artes e ciências (JULIÃO, 2006). O Mouseion de Alexandria, no Egito, foi construído por Alexandre, o Grande, e continha "[...] alguns objetos, como esculturas e instrumentos utilizados pela astronomia; um parque botânico e zoológico; salas de lazer, refeitórios e laboratórios para experimentos científicos; e ainda uma importantíssima biblioteca [...]" (SANTOS, 2006, p. 167), o que demonstra que esses mouseion assemelhavam-se mais aos nossos atuais centros de estudos e pesquisas do que aos museus, sobretudo os históricos e os de arte, na interpretação de Myrian Santos.

No Brasil, as primeiras instituições museológicas surgem após a transferência da família real e sua corte para o território americano em 1808, tendo em vista a necessidade de manutenção da vida cultural cortesã. Para formar tais instituições em solo brasileiro aproveitou-se largamente o conjunto de artefatos trazido pelos nobres portugueses. Em vista disso, Letícia Julião chama a atenção para o caráter enciclopédico de tais instituições. Segundo Julião esses museus eram "caracterizados pelas pretensões enciclopédicas, eram museus dedicados à pesquisa em ciências naturais, voltados para a coleta, o estudo e a exibição de coleções naturais, de etnografia, paleontologia e arqueologia" (JULIÃO, 2006, p.22). Grandes repositórios de curiosidades, nem sempre eram dotados de senso crítico ou mesmo analítico.

Nas primeiras décadas do século XX os museus históricos brasileiros passam a ser compostos também de uma função pedagógica, sobretudo, no que tange à construção de uma nacionalidade brasileira. É nesse contexto ideológico de fortalecimento do sentimento de pertencimento à nação que surge em 1922 no Rio de Janeiro o Museu Histórico Nacional. Sua inauguração aconteceu no bojo das comemorações do $1^{\circ}$ Centenário da Independência do Brasil. Já o Museu Paulista, nesse período sob a direção de Affonso de Taunay, ganha ares de exaltação da nação, optando por um viés regionalista contando a história do Brasil por meio da história dos paulistas, ou melhor, dos bandeirantes, tomados por Taunay, como personificação do espírito paulista (BREFE, 2005). Os museus históricos vão se desenvolvendo no Brasil ao longo do século $X X$, na ânsia de perdurarem memórias e histórias locais, regionais e/ou nacionais.

O Museu Histórico de Londrina Padre Carlos Weiss (MHL) começou a desenvolver suas atividades no ano de 1970 na sede da antiga Faculdade de Filosofia, Ciências e Letras de Londrina, tendo sido incorporado à Universidade Estadual de Londrina em 1974. O ano de 1986 o MHL é transferido para o imponente prédio da Estação Ferroviária, tendo em vista a remoção dos trilhos do centro da cidade e consequente desativação das funções primeiras do prédio. Construído na década de 1950, o prédio da Ferroviária é um marco na paisagem londrinense apresentando uma 
mescla de estilos arquitetônicos, dentre os quais sobressaem-se as linhas arquitetônicas de influência europeia. Sobre o prédio da antiga Estação Ferroviária que hoje abriga o MHL, Zueleide de Paula $(2010$, p. 15) ressalta

\begin{abstract}
Sua expressão estilística se destaca no ambiente urbano, embora Londrina hoje tenha edifícios da arquitetura contemporânea de significativo impacto para uma cidade de porte médio. Visto que seus arquitetos - podemos fazer tal afirmação pelo que indica a imagem urbana - estão atentos aos movimentos estilísticos contemporâneos, mas mesmo assim, não apresentaram uma edificação que viesse a se sobrepor em comparação a esta que hoje abriga o Museu Histórico, como referencial na mídia para identificar a Londrina cantada em versos e prosa.
\end{abstract}

É preciso situar que a década de 1950 é um período de grandes transformações no espaço urbano londrinense, motivadas pelo forte enriquecimento da cidade advindo da valorização crescente do café. Datam desse período construções modernistas na cidade como o Cine Teatro Ouro Verde, a Estação Rodoviária e a Casa da Criança, obras assinadas pelo renomado arquiteto João Batista Villanova Artigas.

A porção setentrional do Estado do Paraná foi objeto de uma ação capitalista racional com o intento de lotear e vender mais de 515 mil alqueires adquiridos do Governo estadual, em 1925, pela Companhia de Terras Norte do Paraná (CTNP), subsidiária brasileira da empresa inglesa Paraná Plantations. A empresa montou escritório na região e a partir de 1929 começou a desenvolver seu projeto de vendas, formando pequenos núcleos urbanos, entre os quais se destaca Londrina. Para tal, a CTNP empreendeu forte campanha propagandista por todo o país e diversas partes do mundo com o propósito de atrair o maior número possível de compradores para suas terras. Os clientes da CTNP vinham atraídos pela fama de fecundidade das terras norte-paranaense e fácil obtenção de riqueza, imagens fortemente difundidas pela CTNP. Essas campanhas que circulavam pelo país e pelo mundo propagavam a ideia de Londrina enquanto uma "terra da promissão" "terra onde se pisa em dinheiro", muito em razão da alta fecundidade da terra "roxa", formando a imagem de um "paraíso terrestre", no qual todos tinham oportunidades para mudar de vida e facilmente enriquece $^{1}$.O projeto foi dividido em lotes rurais e urbanos de tamanho médio, possibilitando mais facilmente a aquisição por imigrantes e colonos de outras regiões do Brasil.

${ }^{1}$ A historiografia já se debruçou largamente sobre essas representações de Londrina empreendidas pela CTNP. Vale destacar os trabalhos de Sonia Adum (1991) e José Miguel Arias Neto (2008). 
Desse modo, a população londrinense aumentou significativamente ao longo dos primeiros anos do desenvolvimento do projeto da CTNP (Tabela 1). Valendo-se desse aumento significativo que uma série de medidas foi tomada no sentido de ordenar o espaço urbano.

Tabela 1 - Crescimento populacional de Londrina

\begin{tabular}{|c|c|c|c|}
\hline ANO & URBANO & RURAL & TOTAL \\
\hline 1934 & 3000 & 4500 & 7500 \\
\hline 1935 & 4000 & 11000 & 15000 \\
\hline 1936 & 7620 & 12907 & 20527 \\
\hline 1938 & 10200 & 18800 & 29000 \\
\hline 1939 & & & 60775 \\
\hline 1941 & 13000 & 82000 & 95000 \\
\hline 1942 & 15000 & 85000 & 100000 \\
\hline 1943 & 18000 & 92000 & 110000 \\
\hline 1944 & 21000 & 31000 & 520002 \\
\hline 1945 & 22500 & 33000 & 55500 \\
\hline 1946 & 25000 & 36000 & 61000 \\
\hline 1947 & 29000 & 38000 & 67000 \\
\hline 1948 & 33000 & 25000 & 58000 \\
\hline 1949 & 35000 & 27000 & 62000 \\
\hline 1950 & 39000 & 33144 & 72144 \\
\hline 1951 & 42000 & 35000 & 77000 \\
\hline 1952 & 45000 & 38000 & 83000 \\
\hline 1953 & 48000 & 42000 & 90000 \\
\hline 1957 & 66500 & 52180 & 118680 \\
\hline 1960 & 72857 & 61964 & 134821 \\
\hline 1970 & 156566 & 72266 & 228832 \\
\hline 1978 & 255931 & 82333 & 338264 \\
\hline
\end{tabular}

Fonte: Arias Neto (2008, p.235).

Londrina era uma cidade que em pouco mais de 20 anos havia crescido expressivamente e se tornado "a capital mundial do café" com milhares de pessoas em um espaço urbano que não estava preparado para tal. Propagavam-se as ideias de higiene social e de progresso, novas instituições eram criadas e se quis formar novos hábitos, assim como novas leis. Para Fausto Lima tratou-se da proposição para Londrina de um estatuto de cidade moderna (LIMA, 2000), tudo no intuito de ordenar a cidade.

\footnotetext{
${ }^{2}$ Há uma significativa redução da população em 1944 devido ao desmembramento de distritos que se tornaram municípios.
} 
A prescrição hábitos de higiene, de normas sanitárias e limpeza e a disciplinarização da moralidade e dos costumes eram assunto de pauta na Câmara municipal, cujas deliberações eram executadas pela Saúde Pública e Polícia de Costumes. "Cabia reprimir a suposta ociosidade dos adultos e, a longo prazo, educar os menores; erradicar os hábitos de moradia dos pobres, consideradas focos de epidemias e terrenos férteis para a propagação de vícios de todos os tipos" (CASTRO, 2003, p.252).

Em Londrina, os aparatos de saúde foram elaborados a partir de 1933 com a construção do primeiro Hospital, que foi construído e administrado pela CTNP, ficou, então, conhecido como "Hospitalzinho da Companhia". Seu modesto tamanho, logo se apresentara insuficiente para a "fronteira em movimento" e para o grande afluxo de pessoas que corria para Londrina. Portanto, em 1936 um grupo organizado fundou um "hospital de emergência" para os indigentes, ou seja, para aqueles que não podiam pagar pelo tratamento no hospital da companhia. O "hospitalzinho dos indigentes" funcionou até 1944, quando foi inaugurada a Santa Casa de Londrina, o primeiro hospital de grande porte com atendimento filantrópico. É propriamente acerca dos elementos urbanos ligados à saúde na história de Londrina que se organiza a exposição do MHL que será analisada a partir de agora.

\section{2 - Cuidar, Curar, Lembrar: Quem cuida? Quem é curado? Quem lembra? Quem é lembrado?}

A exposição "Cuidar, Curar, Lembrar: memória da saúde em Londrina" foi organizada pelo corpo técnico do MHL sob a direção da historiadora Profa ${ }^{-}$Dra. Regina Célia Alegro e marcou também a renovação da iluminação cênica do museu. De caráter temporário, a exposição está dividida em três módulos, de modo que os dois primeiros módulos se ocupam mais da memória e da história enquanto o terceiro - o maior dos módulos - é dedicado a elementos e objetos contemporâneos no que tange à saúde em Londrina.

Antes de descrevermos os ambientes, é preciso destacar que a exposição é apresentada por um texto de abertura, no qual estão expressos os pressupostos aos quais ela se propõe a cumprir. Segue o texto:

A Exposição Cuidar, Curar, Lembrar - Memória da Saúde em Londrina apresenta um olhar cultural sobre os cuidados com o corpo. Aborda desde o ambiente das farmácias antigas e do Hospitalzinho ao consultório do Dr. 
Jonas, abrangendo também aspectos mais atuais relativos à saúde, como iniciativas que dão suporte à vida humana.

Destacam-se práticas de saúde que num contexto de saberes e fazeres tradicionais se entrelaçam, fortalecendo a identidade de diferentes grupos e comunidades.

As abordagens promovem conceitos voltados ao uso sustentável dos recursos ambientais visando a promoção da vida, a prevenção de doenças e a educação para o reconhecimento das formas de saúde como direitos que requerem ações integradas no campo da cultura e da saúde.

Tomamos, assim, conhecimento do que está proposto para as próximas salas. A primeira sala conta com três paredes destinadas à exposição. A primeira delas que o visitante toma vista é a que se situa em frente à porta de entrada e ocupa-se das práticas ditas tradicionais, sobretudo, aquelas relacionadas às práticas religiosa. $\mathrm{O}$ que seria o segundo parágrafo do texto de abertura, se 0 tomarmos como base. Trata-se de uma grande espiral formada pela frase "Deus te abençoe" em 17 diferentes idiomas. Em alguns pontos da espiral mística há sete prateleiras de vidro suportando elementos como um cocar indígena, uma imagem de São Jorge, outra de Ganesha entre diferentes artefatos que remetem a algumas práticas religiosas. Ao lado está um quadro-textual informando que essas práticas são transmitidas pela fé e oralidade.

A continuação desta parede faz-se destacada do alinhamento das demais e encontra-se repleta com cópias de antigos anúncios de jornais. Nesses reclames estão dispostos anúncios de médicos da cidade, de farmácias, de medicamentos contra as mais diversas doenças, mormente, sobre a tuberculose e "lepra". É possível observar recortes de jornais com notícias sobre a atuação do Posto de Higiene e algumas práticas higienistas adotadas pelo município. Os demais espaços desse ambiente são dedicados às antigas farmácias. Em uma delas há uma pintura mural retratando dois farmacêuticos em seu estabelecimento comercial rodeados de frascos e ervas. Em frente desta pintura - que toma por completo uma das paredes - há um balcão com alguns frascos de produtos farmacêuticos. Na parede ao lado estão expostos quadros com anúncios das farmácias ditas pioneiras de Londrina. Há um deles que diz o seguinte:

A primeira farmácia instalada em Londrina situava-se no "Hospitalzinho", como era conhecido o primeiro hospital constituído pela Companhia de Terras Norte do Paraná, em 1933. Em 1934, situadas no Centro da cidade de Londrina, estavam a pharmácia "do Prisciano de Macedo" e "do Gomes". Em 
seguida, nos anos trinta, outras se estabeleceram na cidade: Paraná, Choicar, União, Brasil, N. Sr-a de Lourdes e Maria Izabel.

Como pudemos perceber por meio das citações aqui apresentadas as referências ao chamado "Hospitalzinho" são bastante frequentes. Esse foi o primeiro hospital de Londrina, inaugurado pela CTNP no ano de 1933 antes da elevação a município que ocorreu em dezembro de 1934. Desta forma, além de bastante referenciado desde o texto de abertura, ele era um dos destaques do segundo módulo da exposição. Nesta sala havia uma maquete do hospitalzinho no centro do ambiente. A maquete encontrava-se circundada por diversas fotos que contam "as histórias da saúde em Londrina". São fotos de médicos, enfermeiros, inaugurações, assinaturas de contratos; em geral são momentos de destaque da medicina na cidade.

$\mathrm{Na}$ parede de fundo deste ambiente havia um painel com retratos de 18 médicos de Londrina, com o qual permitia-se certa interatividade com o espectador, uma vez que se podia "abrir" as fotos revelando, assim, uma biografia do retratado. Nesse ponto, queremos fazer a primeira digressão e apontar uma questão de gênero, pois entre os 18 médicos que entendemos tratar-se de personagens influentes na história local, tendo em vista o destaque que ganham na exposição, encontramos os retratos de duas mulheres: $\mathrm{Dr}^{\mathrm{a}}$ - Yolanda Sckowroneck e $\mathrm{Dr}^{\mathrm{a}}$ - Severina Alho. Em suas biografias são relatados seus feitos profissionais e os cargos que ocuparam. Na biografia de Yolanda Sckowroneck consta também breve biografia e fotografia de seu marido, o também médico Dro Ricardo Edgar Sckowroneck. É preciso destacar que esse recurso utilizado reforça uma posição da mulher submetida ao homem, uma vez que mesmo sendo $\mathrm{Dr}^{\mathrm{a}}$ - Yolanda Sckowroneck uma médica destacada na sociedade sua imagem foi associada à do marido, como se legitimasse sua presença naquele quadro, como se validasse assim a homenagem a ela. Nesse sentido é preciso pensarmos,

No entanto, ainda hoje, na sociedade em seu sentido mais amplo, mesmo as mulheres bem-sucedidas profissionalmente - em número cada vez maior hoje em dia - quando casadas, continuam a ser vistas como a Sra. X (por X entende-se o sobrenome do marido). Assim, apesar de, no círculo profissional, ela ser a Dra. Y, [...] nos círculos sociais, de maneira geral, ela torna-se a Sra. X (ROCHA-COUTINHO, 1994, p. 79).

No entanto, o elemento de maior destaque nesse ambiente é o que se situava a extrema esquerda da sala e trata-se de uma reprodução de um consultório médico, mais especificamente trata-se do consultório onde atendia Dr. Jonas Farias de Castro, membro fundador da Associação 
Médica de Londrina. Neste cenário estavam dispostos alguns objetos como mesa, cadeira, diploma, cama médica, instrumentos para atendimentos e cirurgias entre outros artefatos. Não há explicação na exposição sobre a procedência dos objetos, mas os funcionários do museu informavam tratar-se de objetos doados pela família do médico. Voltaremos a discutir esse cenário e suas implicações para a linguagem museográfica adotada pela exposição.

O terceiro módulo é a maior das salas e encerra o discurso trazendo a exposição para a contemporaneidade e debatendo assuntos que são tangentes à vida cotidiana do visitante como as campanhas contra a dengue, a coleta seletiva do lixo, o tratamento de água entre outros. Existem diversos quadros explicativos, alguns com textos sobre variadas temáticas como cuidados alimentares, a importância da atividade física e da boa alimentação, pirâmide alimentar, plantas medicinais, fitoterapia, terapias complementares etc. Tem destaque no final da sala uma maquete de uma subestação de tratamento de água da SANEPAR (Companhia de Saneamento do Paraná).

Todavia, o elemento de maior destaque nesse ambiente é um tablado quadrado disposto no centro da sala e com quatro biombos, um em cada canto. No centro deste tablado havia um balanço com uma boneca representando uma criança. $O$ balanço remete ao modo de pesagem utilizado pela Pastoral da Criança, entidade ligada à Confederação Nacional dos Bispos do Brasil e mundialmente famosa pelo combate à desnutrição infantil. Sua fundadora, a médica Zilda Arns morta em 2010 em um terremoto enquanto atuava em missão no Haiti -, fora indicada ao Nobel da Paz pelo seu trabalho junto às crianças em situação de miserabilidade. Na exposição, além da referência ao modo de atuação da Pastoral, havia um textos dos biombos que afirmava a coincidência da temática da exposição com o tema Campanha Nacional da Fraternidade da CNBB daquele ano de 2012, além de constar no mesmo texto também uma homenagem à Dra. Zilda Arns.

Um desses biombos é destinado às parteiras. Personagens comuns no Brasil e em Londrina até poucos anos -, nesse texto é citada a importância para a família do parto em casa, próximo à família e outra passagem sobre Maria Shimyo Tan, parteira pioneira em Londrina, que se graduou no Japão e desempenhou mais de 10.000 partos em toda a região ao longo de mais de 40 anos de trabalho. $O$ tema maternidade é também presente em uma vitrine com objetos que são utilizados pela Pastoral da Criança como métodos contraceptivos, em verdade, são práticas que possibilitam a mulher tomar conhecimento do seu período mais fértil.

Ao final da exposição, um mural com fotos antigas justapostas a fotos recentes de diversas práticas desportivas em Londrina. Uma bicicleta organicamente colocada em frente a um painel cuja foto, em sépia, retrata uma estrada de chão batido, convidando o espectador/visitante a um passeio de bicicleta pelas estradas da Londrina antiga.

O caminho que percorreremos a seguir não é pelas salas de uma exposição ou de um museu, mas sim pelo campo dos conceitos em História e, mais detalhadamente, sobre os conceitos de história e memória nos museus. 


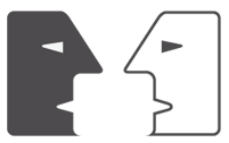

ANTÍTESES

Figura 1- Espiral místico da primeira sala da exposição, farmacêuticos e farmácias presentes

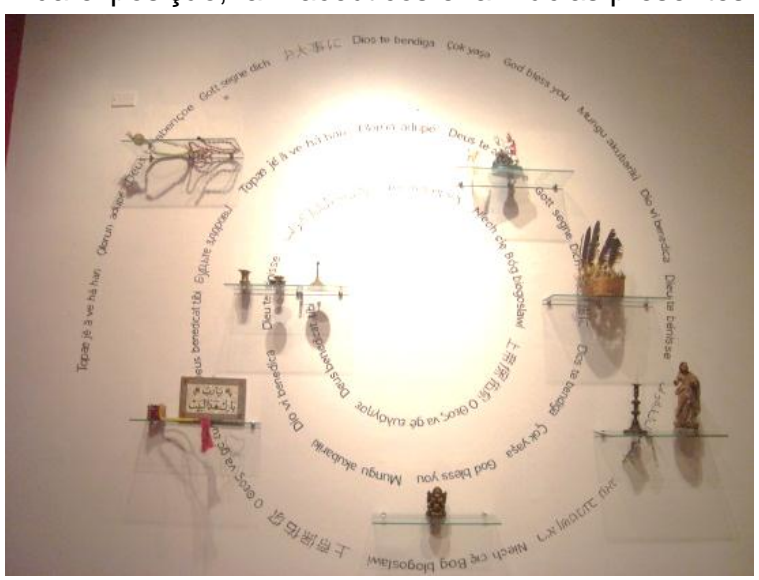

Fonte: Fotos do autor.

Figura 2- Painéis sobre os boticários no primeiro módulo

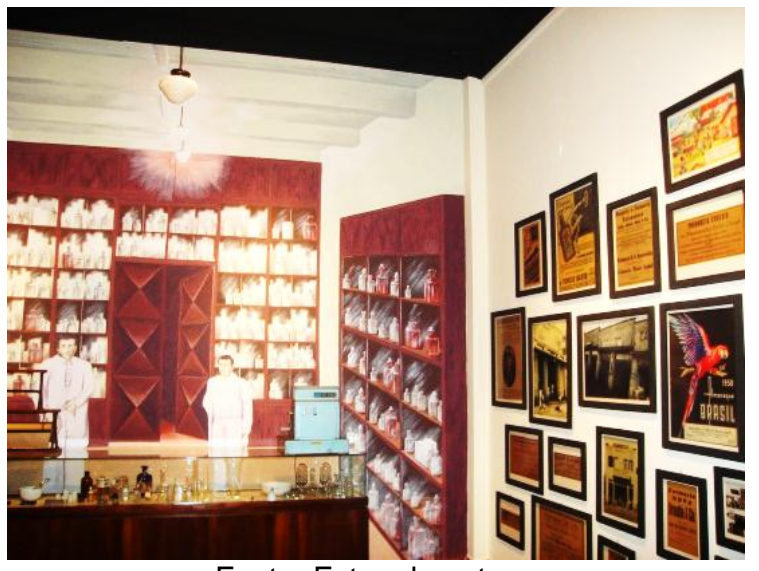

Fonte: Fotos do autor.

Figura 3: Segundo módulo da exposição com o consultório do Dr. Jonas Farias de Castro, a maquete do Hospitalzinho e as fotografias

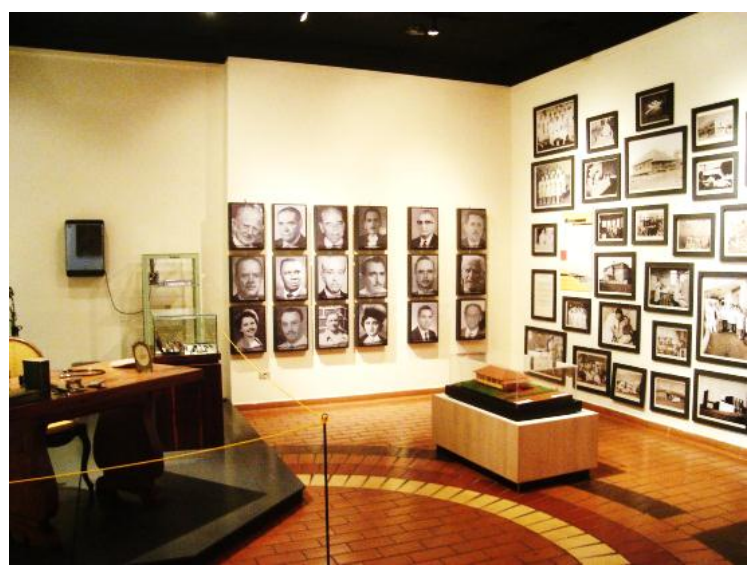

Fonte: Fotos do autor 
Figura 4: terceiro módulo com destaque para o tablado central

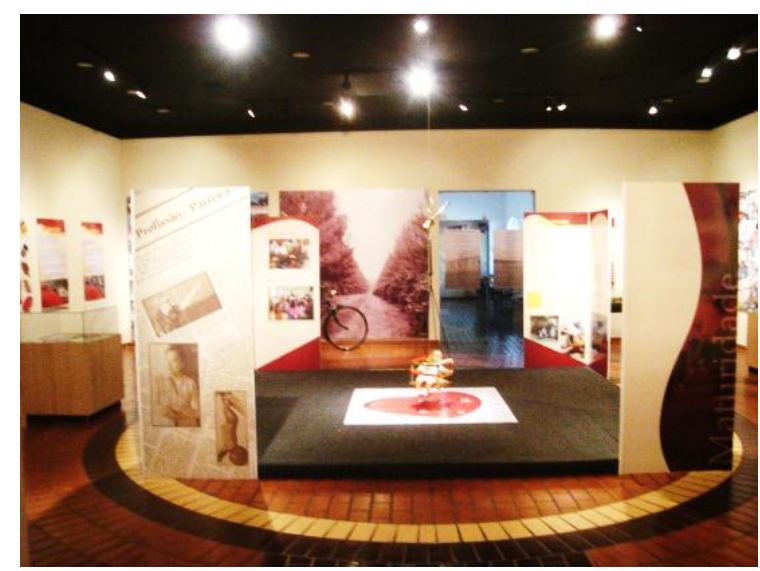

Fonte: Fotos do autor

\section{3 - Entre história e memória: a problemática dos conceitos}

A historiadora Myrian Sepúlveda dos Santos em sua obra "A escrita do passado em museus históricos" nos apresenta as mudanças ocorridas na linguagem museológica de dois importantes museus históricos nacionais: o Museu Histórico Nacional, na cidade do Rio de Janeiro, e o Museu Imperial, em Petrópolis. Apesar de sua análise se circunscrever a esses dois museus e a seus respectivos momentos de reestruturação, o arcabouço analítico proposto pela autora pode ser útil a outras tantas análises de museus históricos, uma vez que ela procura mostrar algumas maneiras possíveis para os museus se apropriarem dos conceitos de história e de memória.

Myrian Sepúlveda dos Santos, então analisando os referidos museus, propõe uma diferenciação de linguagens entre museus-memória e museus-narrativa. Os museus-memória são aqueles que surgem na França do século XVIII em cuja organização há uma valorização da nação. Santos utiliza como exemplo o MHN sob a direção do integralista Gustavo Barroso, que o dirigiu por quase 40 anos. No museu-memória "a preocupação com uma ordenação temporal e a crítica a acontecimentos do passado são inicialmente muito débeis e restritas na historiografia presente no MHN" (SANTOS, 2006, p.45). Dessa maneira "o museu-memória é, portanto, aquele onde observamos que a história, como reconstrução intelectual, laica e universalizante, submete-se ao poder do afetivo e do mágico, à dialética da lembrança e do esquecimento presente na memória" (SANTOS, 2006, p.46). Ou seja, é preciso que se saiba que o conceito de museu-memória para Santos é um museu cuja escrita da história está subordinada a um poder da memória e no qual não há a preocupação com a periodização, os objetos expostos são escolhidos pelo caráter maravilhoso e digno de ser rememorado ou pela evocação do passado que possuem. 
Em contraposição a este conceito de museu, Santos propõe, após análise da escrita da história no MHN pós-Barroso, o conceito de museu-narrativa. A linguagem museográfica no museunarrativa é mais focada na razão histórica. Esse movimento, segundo a autora, é concomitante com uma reavaliação da própria historiografia, suas funções e métodos. Segundo ela,

o Museu [MHN] ganhou uma nova linguagem, rompendo com o passado. Ganhava em história, mas perdia a memória. A nova escrita da história adotada deixou de lado os objetos, já encarados como peças mortas e sem sentido, e passou a utilizá-los como suportes de uma verdade que autorizava o refazer de novos caminhos (SANTOS, 2006, p.62).

Não preocupado com uma história linear e sucessória de eventos na linha do tempo, o museunarrativa preocupa-se em produzir um dado conhecimento histórico, o "culto da saudade" é deixado para trás e, sobretudo, abandona-se a fetichização do objeto. À vista disso, o objeto não é o foco da exposição e o culto aos objetos maravilhosos e dotados de um caráter extraordinário não faz parte dessa nova linguagem museográfica. Para Miryan Sepúlveda dos Santos o museu-narrativa é

[...] aquele que tem a história racional moderna, e não mais a história que se apóia na memória como carro-chefe da exposição. A narrativa [...] subordina o outro elemento da linguagem museológica, que é o objeto. O acervo não é mais quem dita a exposição; ele aparece como auxiliar à narrativa (SANTOS, 2006, p.69).

Como já dissemos, essa conceituação elaborada por Myrian Sepúlveda dos Santos foi baseada em suas análises da escrita da história no Museu Histórico Nacional e no Museu Imperial. Todavia, esses conceitos podem ser utilizados para analisar linguagens museográficas de outras instituições, assim, partiremos para pensarmos o Museu Histórico de Londrina e sua exposição "Cuidar, Curar, Lembrar".

A exposição organizada pelo MHL com a proposta de ser uma "memória da saúde em Londrina", em nossa análise, está orientada de forma a coadunar-se com a concepção de um museu-memória. A exposição está arranjada de maneira personalista, uma que vez que é possível notar um culto não só aos indivíduos, mas aos objetos que, ao longo da exposição, remetem a tais personagens. Como exemplo podemos citar que no primeiro módulo da exposição há a referência aos boticários e farmacêuticos do começo da cidade, mas não se fez apenas menção aos seus 
modos de trabalho, a sua prática ou a sua importância para a cidade. No entendimento do MHL era necessário nomeá-los especificamente, pois só assim esses profissionais "pioneiros" seriam homenageados. No entanto, a exposição seria sobre a memória da saúde em Londrina e não sobre os personagens individualizados.

Outro exemplo bastante contundente é a forma como o segundo ambiente da exposição está organizado, tratando da memória dos médicos da cidade. Para representar os profissionais da medicina de Londrina optou-se por nomear dezoito personalidades e (ins)escrever suas biografias na exposição. Entretanto, o destaque no espaço museológico é dado a outro médico, Dr. Jonas Farias de Castro. Este médico teve seu consultório reproduzido na exposição e sua vida profissional narrada nos textos.

Há um sentido de coadunar-se à ideia de Regina Abreu acerca da fabricação da imortalidade de Miguel Calmon no MHN em 1936, quando a viúva doou para o museu centenas de peças mobiliarias e objetos que pertenceram a ela e o marido. Foram doados diversos elementos que remetiam à vida profissional de Calmon, homem da política do Império e da Primeira República. Não foram doadas fotos do casal ou elementos que revelassem a intimidade da família e do homem Miguel Calmon. Não há, por exemplo, fotos da esposa na exposição. É preciso que se diga que os itens doados eram de grande valor pecuniário, mas acima de tudo, grande valor simbólico - como a adaga de caça do rei Luís XVIII da França - e representavam o Miguel Calmon estadista e homem de governo ligado à nobreza nacional e internacional. Nesse sentido pensamos que a montagem do consultório do Dr. Jonas na exposição transforma-o - assim como transformou Calmon - em um homem-semióforo. Segundo Abreu (1996, p.44),

[...] no topo das sociedades 'encontram-se sempre um ou mais homenssemióforos, que são os representantes do invisível: dos deuses ou de um deus, dos antepassados, da sociedade vista como um todo etc.' Esses homens-semióforos estabelecem uma distância entre eles e os outros, rodeando-se de objetos-semióforos e deles fazendo alarde.

Semióforos são símbolos transcendentes que carregam significações presentes e futuras, ligando-se a diferentes concepções de tempo e espaço, são como portais. Nas palavras de Abreu os "[...] semióforos [são] diferentes das coisas, dos objetos úteis, são objetos destituídos de valor de uso. Singulares, não servem para serem usados, mas para serem expostos ao olhar" (ABREU, 1996, p.43). Deste modo os semióforos são dotados desse significado especial sem valor de uso, seu valor está no seu significado. Ou seja, aqueles instrumentos cirúrgicos dispostos no "consultório" não servem para mais nada hoje, mas significam por terem sido utilizados pelo Dr. Jonas. Nas palavras de Marilena Chauí (2001, p.12): 
Um semióforo é, pois, um acontecimento, um animal, um objeto, uma pessoa ou uma instituição retirados do circuito do uso ou sem utilidade direta e imediata na vida cotidiana porque são coisas providas de significação ou de valor simbólico, capazes de relacionar o visível e o invisível, seja no espaço, seja no tempo, pois o invisível pode ser o sagrado (um espaço além de todo o espaço) ou o passado ou o futuro distantes (um tempo sem tempo ou eternidade), e expostos à visibilidade, pois é nessa exposição que realizam sua significação e sua existência

Assim, entendemos que houve a fabricação - ou a tentativa - da condição de imortal para Dr. Jonas Farias de Castro, mas não apenas dele, como de demais profissionais da saúde presentes na exposição. A transposição e montagem de um cenário que recria o ambiente de seu consultório é, a nosso ver, uma condição de semióforo, pois aqueles objetos unem presente e passado e possuem valor simbólico e representativo. Como dito, há na linguagem adotada pelo museu um culto à personalidade.

É preciso evidenciar que tal caráter está presente em outras estruturas do MHL. Em sua galeria de exposição de longa duração há também outros três cenários que remetem a personalidades locais. O primeiro e mais bem elaborado deles é a recriação do escritório do diretor da CTNP, Arthur Thomas; outro ambiente recriado é o armazém - o primeiro da localidade - de secos e molhados de David Dequeche; e o terceiro é a alfaiataria homônima de Lupercio Luppi. A tendência desse museu-memória é a personificação.

Na exposição temporária podemos analisar que ao invés de mostrar as farmácias antigas, seus instrumentos, suas fórmulas, sua "magia", optou-se por expô-las nomeadamente, ao mesmo modo que se deu com os médicos pioneiros. Construção semelhante se dá no último ambiente, onde um dos biombos é dedicado aos nascimentos e, por sua vez, personificados em Maria Shimyo Tan. $\mathrm{Na}$ exposição há uma citação da obra de Oguido, segundo a qual Dona Maria S. Tan teria realizado mais de dez mil partos ao longo dos 40 anos em que atuou como parteira. Todas as parteiras, assim como os partos que aconteceram fora dos hospitais, estão ali representadas, personificadas por esta parteira.

Contudo, o que se pode perceber é que há um destaque muito grande para a memória oficial, memória que notadamente privilegia um grupo. Esta memória fora oficializada ao longo dos anos por meio dos mais diversos discursos como monumentos, periódicos, livros e comemorações, inclusive o próprio MHL com sua exposição de longa-duração. Essa memória oficializada está fortemente atrelada à Companhia de Terras, seus membros e feitos. Essa visão perdura uma vez que a imagem utilizada para ilustrar a "memória da saúde em Londrina" no cartaz de divulgação da 
exposição é a do "Hospitalzinho", o primeiro hospital de Londrina e construído pela CTNP, mas que, no entanto, se tratava de um hospital privado que não oferecia cuidados médicos àqueles e àquelas que estavam alijados do "Eldorado cafeeiro" e suas benesses. Esse mesmo estabelecimento é recorrente em textos ao longo da exposição. Em face de tamanha importância atribuída a essa memória e à recordação do "hospitalzinho" que há uma maquete do hospital na exposição, para que os visitantes além de ler sobre ele, possam também o ver. Nota-se um empenho em institui-lo como um mito fundador da saúde em Londrina.

Destarte, ainda interrogamos sobre o conceito de história presente na linguagem museográfica do MHL. Similar às concepções de Myriam dos Santos sobre o MHN no Rio de Janeiro entendemos que o MHL permanece atrelado a uma concepção de história-memória. É preciso, portanto, refletirmos sobre as relações entre os conceitos de memória e história, que por diversas vezes são apontados, por publicações ou opiniões do senso comum, enquanto sinônimos. As imbricações entre tais conceitos já foram largamente discutidas pela historiografia a fim de demostrar que elas não podem ser confundidas.

[...] evidencia-se como imprópria qualquer coincidência entre memória e História. A memória, como construção social, é formação de imagem necessária para os processos de constituição e reforço da identidade individual, coletiva e nacional. Não se confunde com a História, que é forma intelectual de conhecimento, operação cognitiva. A memória, ao invés, é operação ideológica, processo psico-social de representação de si próprio, que reorganiza simbolicamente o universo das pessoas, das coisas, imagens e relações, pelas legitimações que produz (MENESES, 1992, p.12).

A história, porque operação intelectual e laicizante, demanda análise e discurso crítico. A memória instala a lembrança no sagrado, a história a liberta, e a torna sempre prosaica. A memória emerge de um grupo que ela une, o quer dizer, como Halbwachs o fez, que há tantas memórias quantos grupos existem; que ela é, por natureza, múltipla e desacelerada, coletiva, plural e individualizada. A história, ao contrário, pertence a todos e a ninguém, o que lhe dá uma vocação para o universal. A memória se enraíza no concreto, no espaço, no gesto, na imagem, no objeto. A história só se liga às continuidades temporais, às evoluções e às relações das coisas. $A$ memória é absoluto e a história só conhece o relativo (NORA, 1993, p.9).

As longas citações acima citadas são basilares para a compreensão do que representam esses conceitos para os historiadores, sendo que a história se dá ao escrutínio, a investigação; enquanto a 
memória deve se tornar fonte para história. Dessa maneira, podemos pensar como essas noções se associam às exposições e aos museus históricos.

Profundamente atrelada à memória, e não à história, a exposição do MHL está vinculada à memória de um grupo, por mais que o discurso seja de empreender uma exposição plural, contemplando diversos setores sociais, essa tentativa pereceu. O que vimos foi uma exposição essencialmente baseada na memória da CTNP, dos "pioneiros" a ela atrelados ${ }^{3}$, pois o conceito de história de Londrina utilizado pelo MHL está bastante associado à atuação da CTNP. Assim, algumas questões ainda nos despertam, como, por exemplo, quem era cuidado, curado por esses médicos?

Essas interrogações nos surgem porquanto que entendemos a exposição bastante asséptica quanto à presença popular. Esse questionamento se dá ao percebemos certas incongruências numéricas. Tomemos em observação a supracitada tabela 1, na qual podemos observar um vigoroso aumento populacional de Londrina. Na própria exposição é narrada a progressão do número de médicos em Londrina e exaltada a inauguração da Santa Casa de Misericórdia em 1944. Vejamos que, em 1944, a cidade de Londrina - sem considerar os novos municípios que surgiam ao redor - já contava com uma população de 52.000 habitantes, número quase $800 \%$ maior que a população de 1934, apenas dez anos antes. E somente com a Santa Casa é que passou a existir um atendimento "público" - no sentindo de não pecuniário - e filantrópico em maior escala, pois como já apontamos o Hospital dos Indigentes era muito pequeno e precário em suas instalações. Isto é, o impressionante número de 43 médicos, 27 dentistas e 24 farmacêuticos, propalado pela exposição em um de seus quadros textuais, não devia ser suficiente ou não estava ao alcance de toda a população, pois muito médicos instalavam-se em Londrina e abriam suas clínicas particulares, como apontou Oberdiek (2011).

Atraída pela justa fama de Londrina muita gente humilde de poucos recursos pecuniários, aqui chega na visão de um futuro melhor, de uma fatia de pão para a prole sem abastança. E esse gente luta, mourejando na gleba portentosa. Luta e vence. Mas há exceções dolorosas. Na gleba ou nas atividades da urbs, há os vencidos. Há os que foram surpreendidos pelas efemeridades traiçoeiras e que tombaram exaustos com o coração amargurado ao lado da esposa soluçante, dos filhinhos famintos ... [...] Pois bem para esses vencidos, enfermos, desvalidos, não há médicos nem remédios na cidade rumorosa, mesmo porque, onde não há possibilidade de

\footnotetext{
${ }^{3}$ Sobre o pioneirismo no Norte do Paraná há grande debate na sociedade e na academia. Esses personagens são tidos como exemplos da bravura e do empreendedorismo, pois são aqueles que chegaram primeiro e desbravaram as terras virgens. Hoje a historiografia relativiza dizendo que são pioneiros não são só aqueles que chegaram e "deram certo", mas também aqueles que vieram para trabalhar no campo, colher o café e muito não conseguiram enriquecer com ele. Para o poder público, pioneiros são aqueles que chegaram entre 1929 e 1939, para tais personagens há um memorial com os seus nomes em 17 totens. Sobre o assunto ver: Arias Neto (1995) e Adum (2009).
} 
remédios, a presença de médicos se torna inútil [...] (PARANÁ NORTE, jul.1940, apud BONI; KOMARCHESQUEI; RODRIGUES, 2010, p.53).

Não teria a população em algum momento tornando-se queixosa dessa situação, reclamando e exigindo melhores condições? Essa informação não nos é apresentada pela exposição.

É preciso pontuar algumas questões a fim de melhor clarearmos o panorama que queremos traçar. O cenário é a Londrina do começo de seu desenvolvimento, ainda cercada pela mata virgem e devoradora e seus novos habitantes precisavam lidar com situações extremas e arriscadas. Assim,

Havia um agravante da situação: as florestas da região geográfica, que compreende o interior do estado de São Paulo e o norte do Paraná, eram endemicamente portadoras de febre amarela e de malária. Portanto, do ponto de vista da natureza, com as endemias e a precariedade das instalações de esgotos e poços de água, o ambiente tornava a situação propícia para o surgimento de doenças (OBERDIEK, 2011, p.77).

Esse panorama descrito por Oberdiek acrescenta-se ao significativo número de migrantes que chegavam a cada ano à Londrina, reforça nosso entendimento de que era preciso um número mais expressivo de médicos. No entanto, os médicos existiam, mas estavam fortemente atrelados à CTNP. Nesse sentido, é também Oberdiek quem nos esclarece sobre a relação da Companhia com os médicos. Segundo o autor "os médicos que foram chegando para desenvolver suas carreiras lamentavam o fato de, nos primeiros anos, a CTNP atuar com autoritarismo e interferir em seus trabalhos" (OBERDIEK, 2011, p.90). Para finalizar essa problemática, com o auxílio da reflexão de Hermann Oberdiek (2011, p.95), concluímos que:

Em um processo de colonização como o da região norte do estado do Paraná, parte importante da população que se deslocava para a região não dispunha de recursos para pagar por atendimentos médicos. Os trabalhadores das frentes dos desmatamentos realizados para a construção das estradas, por exemplo, ou os pequenos agricultores, que empregaram todos os seus recursos na compra das terras, com certeza foram os que mais tiveram problemas. 
A abundância de recursos médicos não era abrangente uma vez que a população londrinense era numerosa e bastante empobrecida, tendo em vista que muitos investiram tudo o que tinham na compra das terras. Essa problemática do empobrecimento e do consequente alijamento do cuidado médica não fora contemplada pela exposição.

Outra questão que nos chamou a atenção, e que também envolve as camadas mais populares, é a abordagem en passant que recebeu o Posto de Higiene. Mais do que o posto, o que queremos destacar é a polêmica em torno do Código de Posturas (Lei Municipal №219 de 31/12/1953). Essa lei, no bojo do pensamento higienista, pretendia promover a higienização da cidade, uma vez do grande crescimento urbano.

Esse processo de higienização do espaço público significava, em última estância, o isolamento da doença, tanto física quanto moral. Assim, cabe à polícia de ordem pública zelar pela tranquilidade dos habitantes e das diversões públicas, reprimindo toda e qualquer atitude que possa atentar contra os bons costumes e a moralidade. (ARIAS NETO, 2008, p.157).

Segundo Arias Neto na esteira dessa legislação seguiu-se o Regime Tributário de Londrina, ordenando o sistema de arrecadação da Prefeitura. No entanto, as mudanças favoreceram os bairros de classe média e o centro, pois as vilas continuaram abandonadas à própria sorte, mesmo assim foram estas camadas sociais que pagaram o ônus.

Desse modo, foram as elites e as classes médias as beneficiadas pelo processo de modernização, sendo que seu custo foi socializado, ou seja, em outras palavras, as classes populares pagaram - através de impostos, taxas e multas - por benefícios que não receberam, e arcaram com o preço de implantação e manutenção da, pesada e burocratizada, máquina administrativa municipal, que sobre elas desencadeou o processo de repressão e banimento, confinando-as aos espaços tidos como adequados na nova ótica urbanista (ARIAS NETO, 2008, p.157).

Os embates entre as camadas da sociedade e as medidas de controle e higienização são mais uma discussão acerca da saúde em Londrina que não foi abarcada pela exposição em análise. 
A memória é seletiva, sabemos. Os monumentos são constructos das sociedades preocupadas em legar imagens de si, entendemos que os museus também o são. A exposição montada não se propôs - oportunamente - a abarcar toda a história da saúde em Londrina, mas explicitou por meio de textos o desejo de açambarcar em sua análise os diversos grupos sociais. O discurso museológico apresentado é monofônico, expressa, ressalta e evidencia a Companhia de Terras e aqueles ligados à elite preponderantemente cafeicultora. Indiferente às massas a exposição privilegia os grandes personagens e negligencia os micro-agentes e os agentes coletivos da história.

Tomando essas considerações acerca da exposição pretendemos pensar a presença das mulheres na exposição, no sentido de perceber como elas foram - se o foram - representadas, tendo em vista que a categoria "pioneira" sempre foi muito vaga, pouco referenciada na historiografia e nos discursos sobre pioneirismos em Londrina. $E$ também pois logo elas foram alvo dos planos higiênicos e sanitários, em razão dos discursos acerca da maternidade. Lembrando que a história oficial é a história da bravura, da coragem e da ousadia, isto é, elementos do espírito humano que tradicionalmente não se coadunam a imagem construída de fragilidade feminina.

\title{
4 -"As mulheres ou os silêncios da História"
}

\author{
No teatro da memória, as mulheres são uma leve sombra. A narrativa \\ histórica lhes dá pouco espaço, justamente na medida em que privilegia a \\ cena pública - a política, a guerra - onde elas aparecem pouco. [...] \\ Assim, os modos de registro das mulheres estão ligados à sua condição, ao \\ seu lugar na família e na sociedade. [...] \\ Em linhas gerais, as "esferas" são pensadas como equivalentes dos sexos e \\ jamais a divisão sexual dos papéis, das tarefas e dos espaços foi levada tão \\ longe. Aos homens o público, cujo centro é a política. Às mulheres, o privado, \\ cujo coração é formado pelo doméstico e a casa (PERROT, 2005, p.45-49).
}

Michelle Perrot procura evidenciar que de acordo com o pensamento normativo o local ao qual as mulheres pertenciam sempre foi o lar, o doméstico, uma vez que este estava em consonância com sua "vocação natural" para a maternidade. Implica-se um problema metodológico para a pesquisa histórica, pois, se os historiadores se fixarem em utilizar apenas fontes que abordem o público, as mulheres provavelmente nelas não estarão contidas em grande expressividade. É 
preciso que haja uma reorientação quanto às fontes ou que o silêncio do espaço público seja denunciado.

Como já dito a exposição "Cuidar, Curar, Lembrar" do MHL orienta-se por um caráter personalista em torno de sujeitos de destaque na sociedade. Ao privilegiar o cuidar e o curar no espaço público via os grandes empreendimentos e personalidades, referindo-se aos hospitais, percebemos que preteriu-se o lugar de maior presença das mulheres, isto é, o lar, o privado.

As mulheres e seus corpos historicamente foram ligados à reprodução humana. Em face da naturalização da disposição biológica da mulher para a reprodução, o papel de mãe foi entendido como vocação natural da mulher. Nos anos 1950 essas representações ficaram mais evidentes, uma vez que havia um esforço de manter a mulher restrita à esfera do privado.

Ser mãe, esposa e dona de casa era considerado o destino natural das mulheres. $\mathrm{Na}$ ideologia dos Anos Dourados, maternidade, casamento e dedicação ao lar faziam parte da essência feminina; sem história, sem possibilidades de contestação. A vocação prioritária para a maternidade e a vida doméstica seriam marcas de feminilidade, enquanto a iniciativa, a participação no mercado de trabalho, a força e o espírito de aventura definiriam a masculinidade. A mulher que não seguisse seus caminhos estaria indo contra a natureza, não poderia ser realmente feliz ou fazer com que outras fossem felizes (PINSKY, 2010, p.609).

A supervalorização da maternidade é acompanhada de uma atribuição, tomada enquanto reconhecimento, de características que seriam indissociáveis às mulheres, como o afeto, a sensibilidade, o cuidado ao próximo.

Assistiu-se, no começo do século $\mathrm{XX}$, a grandes campanhas higienizadoras, nas quais a eugenia $^{4}$ estava bastante presente. Segundo Maria Martha Freire houve um processo de cientifização do lar no qual a mulher deveria tornar-se mãe-cientista. Esse processo situa-se num contexto de louvação da ciência e também da pátria e do futuro pátrio. Desse modo as mães deveriam cuidar atentamente da saúde dos filhos, pois estariam cuidando e contribuindo enormemente para o futuro da nação, de forma que preparavam e criavam o homem do futuro.

\footnotetext{
${ }^{4}$ A eugenia como movimento científico e social cresceu a partir do final do século XIX; tinha como preceito científico o controle das leis da hereditariedade humana a fim de produzir nascimentos desejáveis. Como movimento social, visava promover casamentos entre determinados grupos e desencorajar uniões consideradas nocivas à sociedade.
} 


\begin{abstract}
Estabelecendo uma clivagem entre o saber médico e o saber leigo das mães, os médicos desqualificaram qualquer prática ou experiência que não tivesse fundamento científico e profissional. As mães são vistas com desconfiança e culpabilizadas pela mortalidade infantil, mas também são merecedoras da atenção e dos cuidados médicos. Como as crianças, as mães precisam ser educadas e os médicos atribuem a si essa tarefa por meio de um conjunto de práticas e de uma metodologia própria cujo objetivo é, em síntese, a normalização da maternidade (MARTINS, 2008, p.143).

[...] a influência das mulheres nos destinos do mundo não se daria através de sua atividade política ou do trabalho profissional, mas sim por intermédio de sua atuação como mães, "preparando, no lar, o homens de que necessitamos na vida pública" (FREIRE, 2009, p.142).
\end{abstract}

Como já apresentado, em Londrina houve um movimento higiênico-sanitário, que desde o início da cidade contou com um posto de higiene, a fim de vigiar a saúde pública, sobretudo, em razão do grande número de casos de doenças venéreas e tropicais ${ }^{5}$. Esse pensamento higienista em Londrina converteu-se em legislação, pelo Código de Posturas na década de 1950, como já destacado. $E$ as mulheres, ou como auxiliares dos médicos em casa - a mãe da nação - ou como objetos a seres controlados na rua - as prostitutas - sempre estiveram na mira desses discursos.

O pensamento higienista de maneira geral queria a mulher em casa, na esfera privada. A criação da mãe-cientista foi uma maneira de acabar com as práticas, no que tange ao cuidado com o bebê e a higiene familiar, consideradas arcaicas, que denotavam um atraso à nação. Por fim, tratava-se da perspectiva de que o progresso da nação dependia da permanência da mulher no lar. Essa foi a mesma ideia norteadora para a ação de proibir a lavagem de roupas em público em Londrina na década de 1950, ou seja, por um fim àquela prática tida como arcaica e concomitantemente forçando as mulheres - nesse caso as pobres - a permanecer no interior da casa (CASTRO, 1994).

Outra ausência que detectamos na exposição foi a das curandeiras ou benzedeiras. Há uma parte da exposição na qual se evidencia os saberes tradicionais relacionados, principalmente, às práticas religiosas. São objetos expostos e um texto no qual as benzeduras são mencionadas, mas não as benzedeiras ou benzedores. O saber popular - tradicional - é preterido, pois, mais uma vez, optou-se por enfatizar o público, o saber das elites, ao invés das rezas e unguentos do lar, das avós, das benzedeiras.

Todavia, é imperativo que se diga que foi por meio da saúde que algumas mulheres conseguiram sua projeção para o espaço público rompendo a condição das esferas público/privado

${ }^{5}$ Sobre prostituição, legislação e controle sanitário ver mais em Leme (2009). 
como pensada por Perrot, e a exposição tratou de mostrar essa faceta. Nela aparecem as poucas mulheres médicas, assim como as auxiliares laboratoriais - estas ganharam uma foto. Todavia, as enfermeiras são quem têm mais destaque, até por sua força quantitativa. Um texto que destaca nomeadamente a presença dos primeiros enfermeiros no hospitalzinho da CTNP e o desenvolvimento de uma capacitação específica para esses profissionais.

Outra seara na qual as mulheres participaram e estão representadas na exposição é a filantropia. Atividade, por vezes, bastante ligada à religiosidade, a filantropia se mostrava como um importante meio de sociabilidade das mulheres da elite, além de considerável projeção social.

Herdeira da caridade, representando no Brasil uma ação historicamente vinculada à fé católica, a filantropia representou também o trabalho permitido às mulheres e incentivado pelas revistas femininas como sugestão de reação ao ócio e à frivolidade - comportamentos que adquiriram conotação condenável numa sociedade que almejava ser moderna. A laicização da filantropia, ao esvaziá-la da gratificação espiritual, diferenciou-a da caridade e deslocou seu foco para o bem-comum, o progresso moral e social, reforçando seu vínculo com a sociabilidade. [...] Além de fazer parte da cultura da elite, a filantropia investia-se de caráter cívico, afinado com uma ideologia que the atribuía dimensão estratégica na construção da nacionalidade (FREIRE, 2009, p.67).

A filantropia teve ligeiro destaque em algumas fotos expostas. Vale lembrar que essa é uma representação da elite londrinense, são esposas de cafeicultores, médicos de destaque na sociedade ou funcionários da CTNP, como retratado na imagem 5 . Nesta fotografia que se encontra no segundo módulo da exposição percebe-se um grupo de senhoras elegantemente sentadas em uma reunião. A legenda nos informa apenas o nome de uma delas, Evangelina Bonifácio e Silva. Dona Nina, como era chamada, foi protagonista de importantes campanhas filantrópicas da sociedade londrinense, principalmente, em prol da Santa Casa (duas vezes dirigida por seu marido) e da Casa da Criança - posto de puericultura e Creche. O grupo por ela comandado, de acordo com a legenda, era denominado como "Senhoras Voluntárias de Londrina". Maria Lúcia Mott destaca que é preciso "[...] se repensar a participação social e política das mulheres educadas das camadas médias e das elites na primeira metade do século XX, através das entidades benemerentes" (MOTT, 2001, p.228). 
Figura 5 - "Senhoras Voluntárias de Londrina"

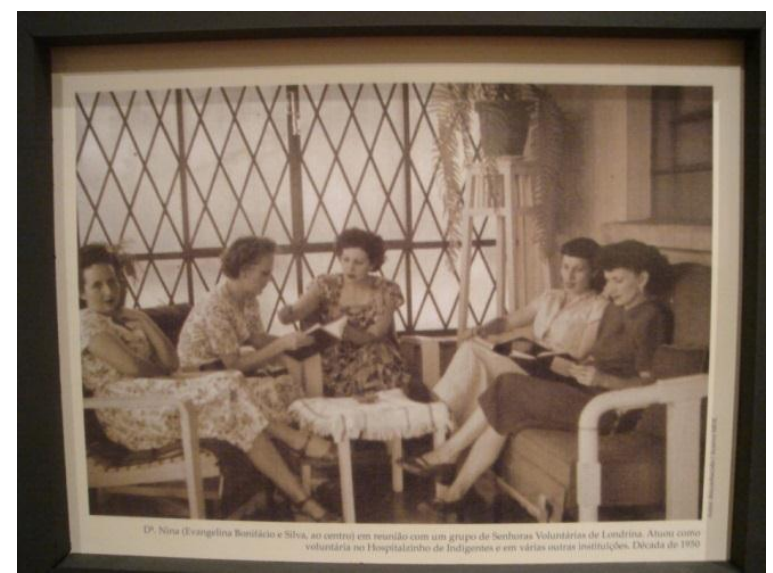

Fonte: Fotografia do acervo do MHL e fotografada pelo autor na exposição "Cuidar, curar, lembrar".

A historiadora Rosimeire Castro procurou mostrar que a filantropia teve um papel importante no começo do desenvolvimento de Londrina, pois "os serviços básicos eram fornecidos aos moradores pelo capital privado da Companhia de Terras Norte do Paraná" (CASTRO, 2003, p.32). Dessa forma a necessidade imediata precisava ser suprida, como a iniciativa de Da. Evangelina na manutenção do "Hospitalzinho dos Indigentes". A ação da filantropia teve um impacto social e de caráter identitário muito forte na vida dessas mulheres.

\begin{abstract}
Através da atuação em sociedades filantrópicas as mulheres redefiniram suas identidades e redescobriram-se como resultado de uma vivência coletiva comum, que as levou à construção de um nós, com relações fundadas na confiança e solidariedade num espaço de consenso e não de contestação.

A filantropia foi para as mulheres uma experiência de muita relevância, que em muitos casos acabou não só por transformar a sua visão de mundo e as ideias que tinham de si mesmas, daquilo que eram capazes de realizar como até mesmo por inseri-las na vida pública (CASTRO, 2003, p 240-277).
\end{abstract}

Para pensarmos a filantropia na história e memória da saúde de Londrina é preciso toma-la enquanto uma "faca de dois gumes", como no ditado popular. A ação filantrópica em Londrina expõe a mulher participativa e atuante na sociedade, se nos aprofundarmos nesse estudo perceberemos que algumas mulheres enfrentaram poderes socialmente bastante estabelecidos como a Igreja e Administração Municipal para levarem seus projetos à diante. Mas também é preciso que se diga que essas ações revelam uma incapacidade da Companhia e da Prefeitura em assistirem digna e propriamente todos - e não apenas uma camada - da população londrinense, certamente, uma temática que não foi explorada pela exposição. 
Dessa maneira, conclui-se que as mulheres estão parcial e minoritariamente representadas na exposição, isso se dá em razão de esta privilegiar o espaço público e, mormente, a memória convertida em oficial. As representações de mulheres ali presentes são, sobretudo, elitistas e/ou daquelas que romperam a esfera do privado para inserirem-se no público, face o caráter personalista da linguagem museológica do MHL. Ao enfatizar essa abordagem o MHL reforça o jogo de luzes e sombras sobre os atores históricos. Está posta uma questão de gênero, pois o feminino foi elaborado no sentido de permanecer ao âmbito privado. Assim, entendemos gênero como estudo das relações entre masculino e feminino, não necessariamente de forma restrita à dialética entre homens e mulheres; e como essas relações são organizadas em diferentes sociedades, culturas e tempos históricos.

"A história, neste caso, é uma narrativa sobre o sexo masculino, e constitui o gênero ao definir que somente, ou principalmente, os homens fazem história" (PEDRO, 2008, p.181). É preciso entender o processo de subjugação das mulheres, agentes históricos que foram vilipendiados como pecadoras, impuras ou então rotuladas como frágeis e indefesas; frequentemente subestimadas e preteridas na política, na economia, no acesso aos direitos e na participação pública. A produção e reprodução de discursos sexistas se deram (se dão) por meio das mais diversas instâncias disciplinadoras e normatizadoras do comportamento feminino como a escola, a religião, a família e a medicina.

\section{5 - À guisa de Conclusão}

Nosso intento ao transcorrermos as salas do Museu Histórico de Londrina e também ao percorrermos conceitos e metodologias do campo da História foi perceber certos discursos presentes na exposição intitulada "Cuidar, Curar, Lembrar - memória da saúde em Londrina".

Entendemos que a referida exposição é dotada de um caráter personalista e essencialmente ligado ao espaço público. Mais do que isso, a memória - no singular - que a exposição propõe é elitista, vinculada à Companhia de Terras Norte do Paraná e aos "pioneiros" que a cercam até hoje em forma de culto. Essa linguagem utilizada pelo MHL na referida exposição é dissonante da diversidade e pluralidade às quais ele anunciadamente se propunha com tal montagem museológica. Devido à opção pela abordagem dos aspectos públicos do cuidar, do curar e, sobretudo, do lembrar, há um reforço de personagens já oficializados por outros tantos discursos. Esses personagens são homens, com poucas exceções ao longo da exposição. Por que montaram o consultório de um famoso médico da cidade e não a cozinha das avós - uma personagem plural e não personalista capaz de engendrar discussões sociais e de gênero -, onde tantos chás, unguentos e emplastros foram preparados por séculos? Essa memória que a exposição apresenta é bastante voltada à elite, principalmente, aos homens; aspectos já bastante consolidados enquanto oficial. 
Todavia, a crítica não é finita e única e tão pouco demeritória. Há nos últimos anos um esforço do MHL em adotar novas linguagens museológicas, assim como, desvencilhar-se de agentes frequentemente focalizados pela historiografia tradicional e por discursos memorialistas. Entende-se que diversos vetores de força agem sobre a organização de uma exposição e que a memória é um campo de batalha, sempre o será. É preciso evidenciarmos a força simbólica que o reforço a dadas memórias pode ocasionar para a própria sociedade. O MHL é um museu local, portanto, suas atividades concernem a memória e história da cidade, assim, na esteira de Ulpiano de Meneses nos perguntamos: Qual cidade é essa apresentada pelo Museu Histórico de Londrina?

Qual cidade? A cidade dos antepassados, dos heróis fundadores (e dos vilões?), dos donos do poder, de ontem e de hoje? Ou conforme a fonte de informação, a cidade dos eruditos e dos historiadores, dos poetas oficiais, dos urbanistas, planejadores e tecnocratas? Dos habitantes? Quais? Do homem da rua e daquele que com suas mãos a constrói, simples instrumento? (MENESES, 1985, p.199).

\section{Referências}

ABREU, Regina. A fabricação do imortal. Memória e estratégias de consagração do Brasil. Rio de Janeiro: Rocco: Lapa, 1996.

ADUM, Sonia M. S. L. Imagens do Progresso: Civilização e Barbárie em Londrina 1930/1960. 1991. Dissertação (Mestrado em História) - Unesp, Assis, 1991.

Práticas discursivas, patrimônio e memória: Monumento Memorial do Pioneiro. IN: SILVA, Claudia. MORAES, Vanda (Org.). Encontro Cidades Novas: a construção de políticas patrimoniais. Londrina: Edição Humanidades, 2009.

ARIAS NETO, José Miguel. O Eldorado: Representações da política em Londrina: 1930 - 1975. Londrina: EDUEL, 2008.

Pioneirismo: discurso político e identidade regional. História e Ensino: revista do Laboratório de Ensino de História da UEL, Londrina, n. 1, p. 69-82, 1995.

BREFE, Ana Cláudia Fonseca. O museu Paulista: Affonso de Taunay e a memória nacional. São Paulo: Ed. UNESP; Museu Paulista, 2005. 
BONI, Paulo César, KOMARCHESQUEI, Bruna M.; RODRIGUES, Natália de Fátima. O papel do Paraná Norte na construção da Santa Casa e o esporte nas ondas do rádio: duas experiências históricas da imprensa londrinense. Londrina: EDUEL, 2010.

CASTRO, Rosimeire Ap. A. O cotidiano e a cidade: práticas, papéis e representações femininas em Londrina (1930 - 1960). 1994. Dissertação (Mestrado em História) - UFPR, Curitiba, 1994.

Ecos da Memória: uma contribuição à história da vida quotidiana de mulheres no Paraná (1930/1975). 2003. Tese (Doutorado em História) - PUC-SP, São Paulo, 2003.

CHAUÍ, Marilena. Brasil: mito fundador e sociedade autoritária. São Paulo: Editora Fundação Perseu Abramo, 2001.

FREIRE, Maria Martha de Luna. Mulheres, mães e médicos: discurso maternalista no Brasil. Rio de Janeiro: FGV, 2009.

HARTOG, François. Tempo e Patrimônio. Tradução: João Carlos Reis. Varia História, Belo Horizonte, v.22, n.36. p. 261-273, jul/dez., 2006.

JULIÃO, Letícia. Apontamentos sobre a história do museu. In: BRASIL. Ministério da Cultural. Instituto do Patrimônio Histórico e Artístico Nacional. Departamento de Museus e Centros Culturais. Cadernos de diretrizes museológicas. Belo Horizonte: Secretaria de Estado da Cultura, 2006. p.1730 .

LEME, Edson H. Noites llícitas: histórias e memórias da prostituição. Londrina: EDUEL, 2009.

MARTINS, Ana Paula V. "Vamos criar seu filho": os médicos puericultores e a pedagogia materna no século XX. História, Ciências, Saúde-Manguinhos, v. 1, p. 135-154, 2008.

MENESES, Ulpiano Bezerra. O museu na cidade $X$ a cidade no museu: para uma abordagem histórica dos museus de cidade. Revista Brasileira de História, São Paulo, v. 5, n. 8/9. p.197-205, set. 1984/abr.1985.

A História, cativa da memória? Para um mapeamento da memória no campo das ciências sociais. Revista Estudos Brasileiros, São Paulo, v. 34, p. 9-29, 1992.

MOTT, Maria Lúcia. Maternalismo, políticas públicas e benemerência no Brasil (1930-1945). Cadernos Pagu, v. 16, p.199-234, 2001.

NORA, Pierre. Entre memória e história: a problemática dos lugares. Tradução: Yara Aun Khoury. Projeto História, São Paulo, n.10, p.07-28, dez.1993.

OBERDIEK, Hermann I. Serviços Médicos: em Londrina (1933 a 1971). Londrina: EDUEL, 2011. 
OGUIDO, Homero. De imigrantes a pioneiros: A saga dos japoneses no Paraná. Curitiba: Ipê, 1988.

PAULA, Zueleide C. Os marcos urbanos em história e memória: o Museu Histórico de Londrina "Pe. Carlos Weiss" em breve nota. Boletim Museu Histórico de Londrina: Londrina, v. 1, n. 2, jan/jun. 2010.

PEDRO, Joana Maria. Historicizando o gênero. In: FERREIRA, A. C., BEZERRA, H.G. e DE LUCCA, T. R. (Org.). O historiador e seu tempo: encontros com a história. São Paulo: Ed. UNESP: ANPUH, 2008.

PERROT, Michelle. As mulheres ou os silêncios da história. Tradução de Viviane Ribeiro. Bauru: EDUSC, 2005.

PINSKY, Carla B. Mulheres dos anos dourados. In: DEL PRIORE, M.; PINSKY, Carla. B. História das Mulheres no Brasil. 9.ed. São Paulo: Ed. Contexto, 2010.

ROCHA-COUTINHO, Maria Lúcia. Tecendo por trás dos panos: a mulher brasileira nas relações familiares. Rio de Janeiro: Rocco, 1994.

SANTOS, Myrian, Sepúlveda. A escr do passado em museus históricos. Rio de Janeiro: Garamond, Minc, IPHAN, DEMU, 2006.

Recebido em 30.09.2014 - aprovado em 20.08.2015. 